\title{
Minimization of Contacts with Students During Covid-19 in an Automatic and Transparent Assessment Process of Exams Organized with Personalized Thesis Randomly Generated Via Microsoft Word
}

\author{
Loreta Kuneshka $^{1 *}$, Marjola Puka ${ }^{2}$, Astrit Bardhi ${ }^{3}$, Romeo Teneqexhi $^{4}$ \\ ${ }^{1}$ Lecturer of Statistics Medical University of Tirana, Albania, UniversitetiiMjekësisëiTiranës, Rruga e Dibres, \\ Tirana, Albania \\ ${ }^{2}$ Lecturer of Electrotechnics, Theory of Electro-Magnetic Field Tirana Polytechnic University, Albania, \\ UniversitetiPoliteknikiTiranës, Sheshi "Nënë Tereza”, No 4. Tirana, Albania \\ ${ }^{3}$ Lecturer of Electrical Machine Tirana Polytechnic University, Albania, UniversitetiPoliteknikiTiranës, Sheshi \\ "Nënë Tereza", No 4. Tirana, Albania \\ ${ }^{4}$ ex Director of Distance Education Centre Tirana Polytechnic University, Albania, Universiteti \\ PoliteknikiTiranës, Sheshi “Nënë Tereza”, No 4. Tirana, Albania
}

*Corresponding Authors: Loreta Kuneshka, Lecturer of Statistics Medical University of Tirana, Albania,UniversitetiiMjekësisëiTiranës, Rruga e Dibres, Tirana, Albania

\begin{abstract}
Exams assessment is one of the most tedious work for university teachers all over the world. Multiple choice theses make exams assessment a little bit easier, but the teacher cannot prepare more than 3 4 variants; in this case, the possibility of students for cheating from one another becomes a risk for "objective assessment outcome". On the other hand, even when the exams are organized with multiplechoices, the time for student's outcome takes up relatively too much time. We have developed a platform which tries to eliminate the time-range and is appropriate for big-sized classrooms testing. It works as follows: The teacher prepares for every exam-question, a JPG file, in simple words precisely an e-picture, preferably with the same dimensions for all photos. It is easy to make use of sniping tool from windows. Let us consider the exam-paper will contain 60 questions / exercises (can be up to 100). Every student will have all these 60 questions / exercises in his/her thesis, in a uniquely personalized version, but randomly ordered by computer. This means that every thesis / exam-paper has the corresponding unique solution key for the outcome, and only the computer knows it, by using the same combine logic with every generated variant of exam-paper. Consequently, the teacher prepares $60 \mathrm{JPG}$ photos which are saved in USB memory stick folder. With this USB, teacher presents to the faculty secretary (printing centre) the number of students he/she has and the folder where the photos are stored in the relevant USB. An operator, at teacher's presence, automatically generates and prints 60 different versions of the exam - papers, using Microsoft Word with a special macro code written in Visual Basic in order to design the proper page making. The secretary also prints a personalized answer sheet, with a student photo for everyone. It is very important for e-students, because minimum time is needed for student's authentication during exams. All answer-sheets are automatically scanned via "SEKRETAR" software (Copyright Romeo Teneqexhi, ZSHDA) and the outcome is generated immediately after the exam procedures. The process could also be handled by the secretary, but it can be used by the teacher himself in the exam classroom. The teacher only needs a laptop and a simple scanner in exam classroom. For the future, we plan to substitute this laptop-scanner-system with the teacher's smart phone. All the above services and provisions can be offered to all teachers by logging to a web platform.
\end{abstract}

Keywords: Scanner based assessment, personalized thesis

\section{INTRODUCTION}

The authors are teachers in different universities in Tirana, Albania. We all like our profession and are very dedicated to teaching. There are two main reasons why we started working on this project: For many years in Albania entering the university as a student has been arranged through a competition process. This process is similarly like organizing exams with considerable numbers of students. Every faculty used to organize its own test, by occupying its teachers for assessment. For objective 
assessment reason, these kinds of exams have been organized by using secrete barcodes. Many university teachers were involved into the assessment process, because the assessment has been performed manually. A pretty long time was needed to announce the results to the students. In some cases, we have encountered corruption problems. Most of the time, the tests have been multiple choice question type. Preserving the secrecy of the "solution key" has been a big problem. The second reason for initiation of this project is the fact that even in the course of the normal exams, at times students try to copy from each other. To avoid the negative phenomena, we have developed a full system for preparing individual (personalized) theses with the same set of questions for all students. Students give the answers by completing the personalized answer sheet and the outcome is given immediately after the exam. This is carried out by the teacher himself in exam-classroom by using a simple scanner and a laptop. The system we have set up is an infrastructure offered to the teachers to help them prepare, organize and successfully finalize the exams. We have conceived the whole aligned process as a chain where the first and the last link is the teacher. With the other links in between, common infrastructure used to help in the process. Let us clarify the following steps.

\section{Preparation OF THESIS}

Let us suppose you represent the teacher and want to use our infrastructure to organize a multiplechoice question exam with randomly, 60 questions (the system provides exams up to 100 questions). All you have to proceed is just to put in a USB folder $60 \mathrm{JPG}$ files (or photos with other words). It does not matter on how you produce these files by scanning, taking pictures by smart phone, grabbing from computer screen, exporting from a graphic software, etc. (the easiest way is by cropping a piece of computer screen using "sniping tool" in windows 7 or later version). It is important to name these files like this: "exercise01+10-3.jpg", "exercise02+3-1.jpg", "exercise03+6-2.jpg", and so on. If you see between "exercise" and ".jpg", there is the information included in the name of the file. What does it mean? The number immediately after "exercise" means the number of exercise (in our case study, 01 to 60). This number is very important for future reference during the whole process. The information " $+3-1$ " for example in "exercise02+3-1.jpg" conveys this meaning: If the student finds the right answer, he/she takes 3 points plus. If the student gives the wrong answer he/she takes 1 point minus. The "minus number" in the name of the file is optional, but "plus number" is obligatory. By leaving all options empty or giving more than one answer, is also penalized by "negative number". Option "I don't know" must be in all exercises (zero point resulting for this answer). This system is preferably chosen to avoid passing the exam, by giving random answers from the students. On the other hand, this gives the possibility to have in exam, exercises of graded difficulty and weight. The information "plus number" / "minus number" must be visible for the student for every exercise, certainly, according to the information in the file name. If the teacher wants, he/she can add notice inside the exercise image for example (with explanation). This means that the students must have written in the notebook, the explanation of the corresponding answer. In this case, after computer assessment, the teacher can review the outcome checking for randomly finding the right answer by the student. All these 60 exercises are ordered, as mentioned in the name of the file make so-called "VARIANT ZERO". All the students have to answer these 60 exercises, but they will have them ordered in different manner. Nobody will have "variant zero" in exams. This is only for the teacher. According to "variant zero", the teacher must prepare the so-called "solution key" which will be used later for the assessment by the computer.

\section{VARIANTS GENERATION}

After the teacher has saved all exams images in a separated folder in a USB memory stick, he/she has to go to the printing centre of the Faculty, where the system of theses generation is available. The number of students and the folder where the photos are located in USB as mentioned above, is the only information the operator wants to know for preparing different variants for every student. The operator, at teacher's presence, automatically generates and prints for each student a different version of the exam thesis, using Microsoft Word equipped with a special macro code written in Visual Basic. Only the computer knows how the thesis is mixed in each version. Every version of thesis is named automatically as "version 001 ", "version 002 ", "version 070 " etc. The operator also prints a "variant zero" of the thesis and this is only for the teacher. He will use it to prepare the KEY solution of these. In figure below are shown variant 491 and 492 of a these, with 14 exercises. The composition of the page is flexible and easily configured by the operator. 
Minimization of Contacts with Students During Covid-19 in an Automatic and Transparent Assessment Process of Exams Organized with Personalized Thesis Randomly Generated Via Microsoft Word

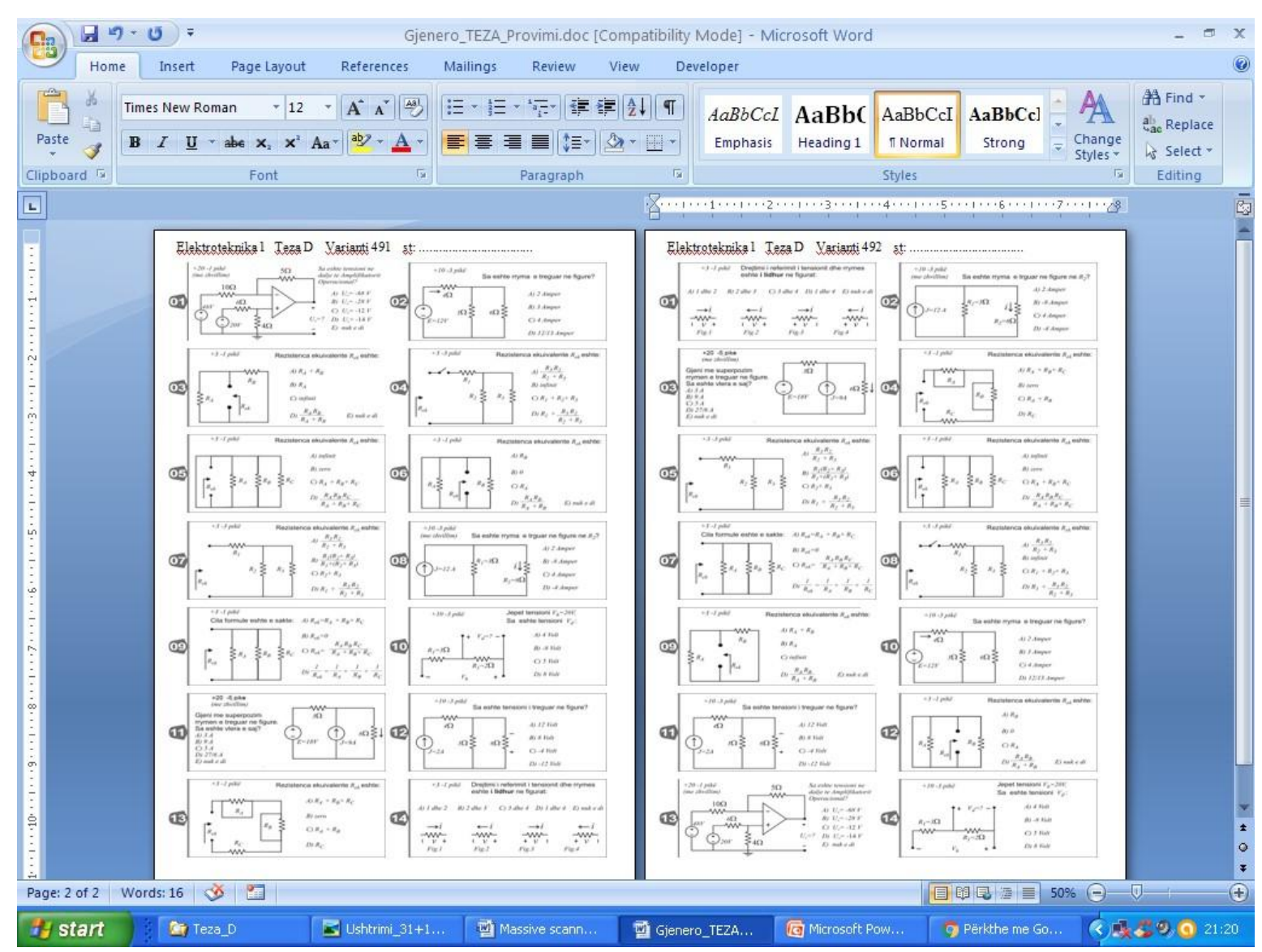

Figure1. Two exam variants automated generated via Microsoft Word

\section{Printing AnSWer Sheets}

The system we have developed is closely related with the secretary of the university. The teacher informs the secretary for the exams, at least, two hours before the exam takes place. The "SEKRETAR" software which is installed in our university is capable to print in minutes the personalized answer sheets, with student's photo, for every student of the Study Course. Every answer sheet is a unique one, with a unique serial number. The answer sheet can also be printed without personalization, simply with a unique serial number. This number will serve to identify the student who fills out the form. The answer sheet contains graphic elements for identification by the scanner and spaces for putting personal data by the student. The student has to full fill this sheet according to the personal thesis. By using this answer sheet, you can arrange up to 4 different subject exams in one classroom (Thesis A, B, C, D). Student has to declare on the answer sheet his/her variant number of thesis, give the answer of the question and sign next to his name. If the answer sheet is not personalised the student must write down his/her name and signs.

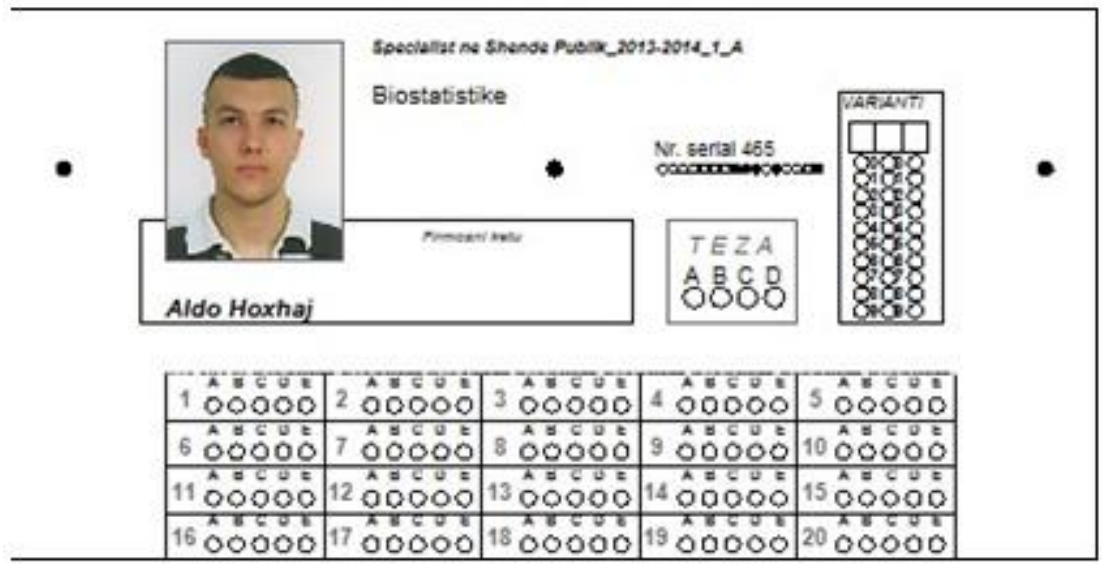

Figure2. Personalized answer sheet 
Minimization of Contacts with Students During Covid-19 in an Automatic and Transparent Assessment Process of Exams Organized with Personalized Thesis Randomly Generated Via Microsoft Word

\section{SCANNER BASED ASSESSMENT}

As it is mentioned above, every student has in the exams, his personalized answer sheet, one thesis and the notebook. He has to give all the answers of exercises to the answer sheet by making a black spot inside the corresponding circle. When he finishes the exam, he gives to the teacher the answer sheet which is scanned by the software "SEKRETAR". If there are problems while completing the answer sheet, they can be corrected by the student before he leaves the exam room. After the last student completes the exam, the teacher is ready to give the preliminary result / outcome to the student immediately. It means every student knows the points he/she has collected. The final assessment can be arranged by the teacher later, or immediately after the exam. It is up to the teacher. All data generated by the scanning process are automatically saved, in an excel file. Teachers can make use of them for different statistical purposes and conclusions in assessments.

\section{EXAM's RESUlts DECLARATION RESPECTING PRIVACY}

In Albanian universities, the results of the exam are given while preserving the privacy of students. The student has the right to dispute the result or to ask for clarification on how to assessment is done. In pandemic conditions this process can lead to the spread of the COVID-19 virus. Organizing the exam with MCQ (Multiple Choice Question) and the techniques we have built make the contact of the students with the lecturer after the exam unnecessary. The student just needs to visit the sitewww.bitalbania.com, click on the link "EXAM ASSESSMENT by scanner" and input in the next coming page the Serial Number and his/her exam's VARIANT. On this page the student can see the way of shuffle of the questions in his/her variant (Figure 2) and the answer sheet with coloured detailed notes for each question made by the computer on his/her scanned answer sheet (Figure 3.a). From this page the student can download a PDF document where all the exact answer of the variant 000 are showed. By crossing the information of the shuffled table, PDF document and his/her answers given on answer sheet the students be convinced of total point gathered in exam (Figure 3.b).So, there is no need to meet the teacher for taking the result. Our students get the result (just gathered points)immediately after the exam, only some clicks are needed on the internet. After manually reviewing the notes of the student on the note book the teachers after necessary verifications make the correction for each student and decide for the formula which will be used for converting points gathered to the mark.In a second step we just update on the internet each scanned answer sheet adding the mark beside points. At the end of theanswers table our software automatically sticks the plot of the way of points are converted to mark (Figure 3.b).

\begin{tabular}{||c||c||c|c|c||}
\hline \multicolumn{5}{|c|}{ Renditja e pyetjeve në variantin 473 } \\
\hline \hline $\mathbf{1}(P 36)$ & $\mathbf{2}(P 22)$ & $\mathbf{3}(P 18)$ & $\mathbf{4}(P 39)$ & $\mathbf{5}(P 28)$ \\
\hline \hline $\mathbf{6}(P 47)$ & $\mathbf{7}(P 44)$ & $\mathbf{8}(P 9)$ & $\mathbf{9}(P 41)$ & $\mathbf{1 0}(P 20)$ \\
\hline \hline $\mathbf{1 1}(P 25)$ & $\mathbf{1 2}(P 33)$ & $\mathbf{1 3}(P 10)$ & $\mathbf{1 4}(P 12)$ & $\mathbf{1 5}(P 15)$ \\
\hline \hline $\mathbf{1 6}(P 48)$ & $\mathbf{1 7}(P 31)$ & $\mathbf{1 8}(P 19)$ & $\mathbf{1 9}(P 13)$ & $\mathbf{2 0}(P 42)$ \\
\hline $\mathbf{2 1}(P 5)$ & $\mathbf{2 2}(P 26)$ & $\mathbf{2 3}(P 4)$ & $\mathbf{2 4}(P 7)$ & $\mathbf{2 5}(P 2)$ \\
\hline \hline $\mathbf{2 6}(P 45)$ & $\mathbf{2 7}(P 34)$ & $\mathbf{2 8}(P 46)$ & $\mathbf{2 9}(P 23)$ & $\mathbf{3 0}(P 37)$ \\
\hline \hline $\mathbf{3 1}(P 24)$ & $\mathbf{3 2}(P 11)$ & $\mathbf{3 3}(P 29)$ & $\mathbf{3 4}(P 21)$ & $\mathbf{3 5}(P 3)$ \\
\hline \hline $\mathbf{3 6}(P 6)$ & $\mathbf{3 7}(P 14)$ & $\mathbf{3 8}(P 40)$ & $\mathbf{3 9}(P 32)$ & $\mathbf{4 0}(P 30)$ \\
\hline \hline $\mathbf{4 1}(P 43)$ & $\mathbf{4 2}(P 17)$ & $\mathbf{4 3}(P 35)$ & $\mathbf{4 4}(P 38)$ & $\mathbf{4 5}(P 27)$ \\
\hline \hline $\mathbf{4 6}(P 16)$ & $\mathbf{4 7}(P 1)$ & $\mathbf{4 8}(P 8)$ & & \\
\hline \hline
\end{tabular}

Figure2. The order of questions in variant 473 
Minimization of Contacts with Students During Covid-19 in an Automatic and Transparent Assessment Process of Exams Organized with Personalized Thesis Randomly Generated Via Microsoft Word
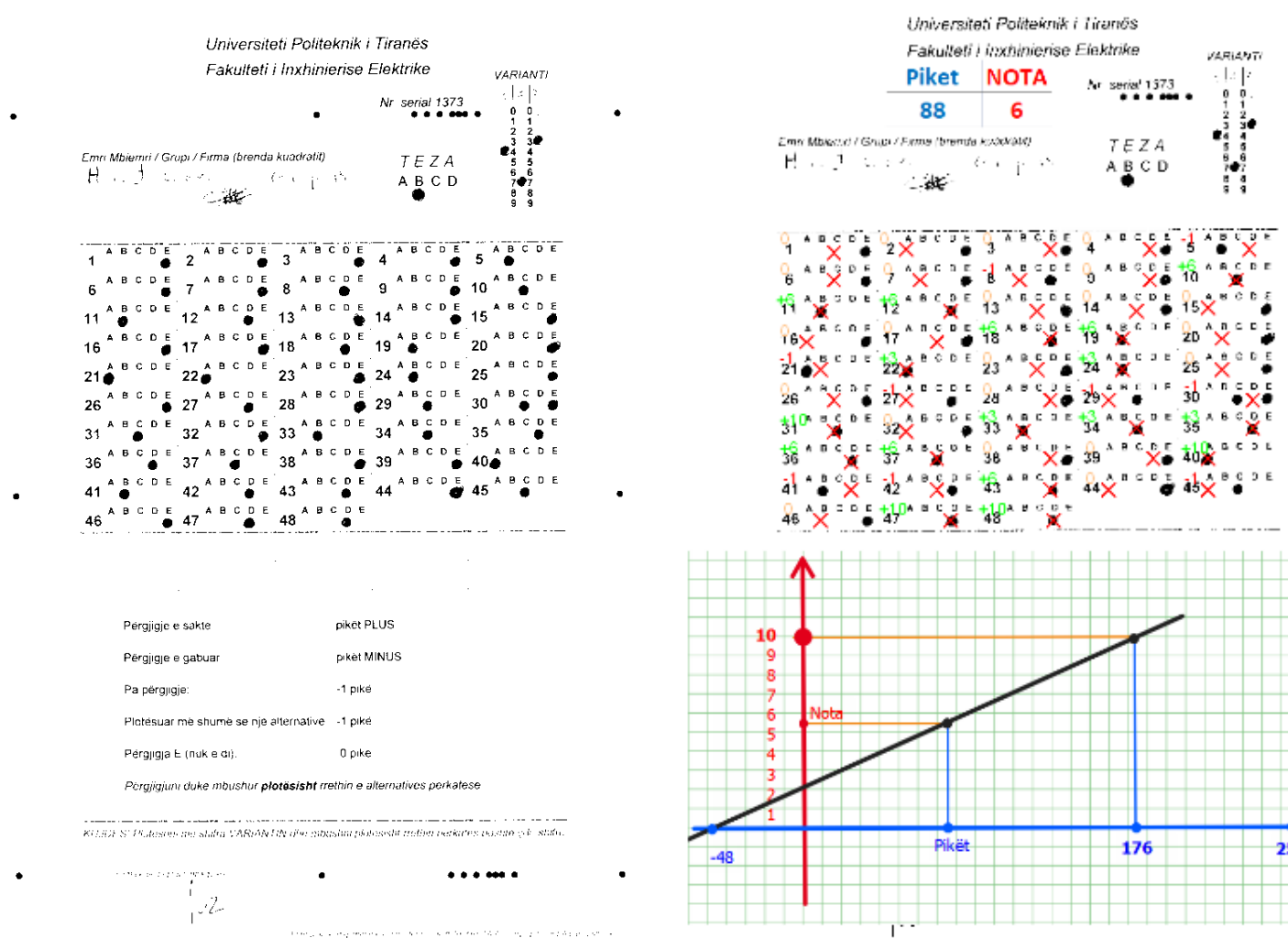

Figure3. $a / b$. Scanned answer sheet (a)assessed and updated after the verification (b)

\section{Penallty Discution}

Paragraph 2 mentions the fact of negative evaluation of the wrong answer. Many students see this as a bad thing. In fact, it is not so. If someone gives random answers to the exam questions, he will probably accumulate zero points if all the questions are with 4 alternatives one of which is correct and the weight of points for each question is $+3-1$. On the other hand, in everyday life, when people make mistakes, they are often penalized in relation to the negative consequences they cause. The student must be prepared in school with the experience of penalization if he errs. The choice of alternative 5 in each question is evaluated with zero points. So, he has the option to say "I don't know" instead of making mistakes. Letting the answer without answer is also penalised with corresponding negative points of the question. The graph below shows the different exam evaluation schemes with 48 questions. Some of the questions are $+3-1$ points, some $+6-1$ points and the rest +10 1 points.In the Figure 4 is shown the case of exam we are discussing. The diapason of points is from minus 48 to 255 . Line (1) is the case giving maximum grade with maximum points, without penalty. Line (2) is the case the lecturer has decided to maximally assessed the student who has accumulated 176 points. In this case the favouring of other students is done proportionally. From the lines of the Figure 4 is clear that, for the same amount of points accumulated, the evaluation according to the scheme with penalty - line(3), for the student is more favourable than the one without penalty.

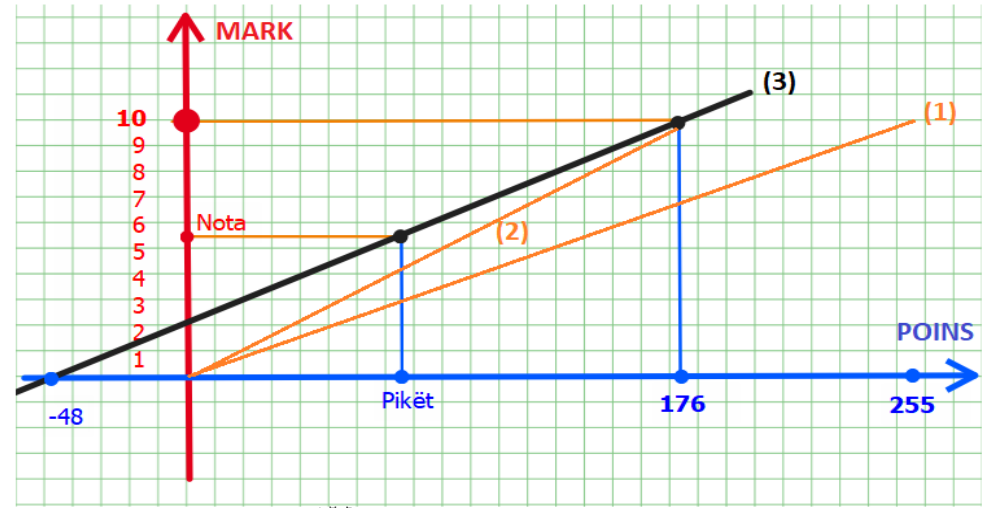

Figure4. Scanned answer sheet (a) assessed and updated after the verification (b) 


\section{Final Declaration}

The authors of this article and several colleagues have used this system in their exams, and the results have been nearly the same with the traditional exams assessment. The students are very much satisfied with this technique and we recommend this soft system to be spread into other Albanian universities. For the future, we plan to substitute this laptop-scanner system with teacher's smart phone. All services for the teachers, as mentioned above, can be also offered by a web platform or by an application easily installed in smart phone from Play Store or App Store.

Citation: Loreta Kuneshka, et.al., "Minimization of Contacts with Students During Covid-19 in an Automatic and Transparent Assessment Process of Exams Organized with Personalized Thesis Randomly Generated Via Microsoft Word" International Journal of Managerial Studies and Research (IJMSR), vol 9, no. 2, 2021, pp. 33-38. doi: https://doi.org/10.20431/2349-0349.0902005.

Copyright: () 2021 Authors. This is an open-access article distributed under the terms of the Creative Commons Attribution License, which permits unrestricted use, distribution, and reproduction in any medium, provided the original author and source are credited. 